\title{
Analisis Potensi Sungai Bawah Tanah Ngancar untuk Pemanfaatan Sebagai Sumber Air Minum
}

\author{
Nuringtyas Yogi Jurnawan, Setyawan Purnama, dan Ahmad \\ Cahyadi \\ Departemen Geografi Lingkungan, Fakultas Geografi, Universitas Gadjah Mada \\ Yogyakarta
}

\section{Intisari}

Air merupakan kebutuhan yang sangat penting bagi manusia. Sayangnya, seringkali air tidak tersedia dengan jumlah dan kualitas yang cukup di suatu wilayah. Mataair dan sungai bawah tanah di kawasan karst memiliki peranan yang sangat strategis dalam penyediaan air bersih khususnya air minum. Penelitian ini berusaha untuk melakukan analisis kuantitas dan kualitas air di Sungai Bawah Tanah Ngancar di Kecamatan Karangmojo, Kabupaten Gunungkidul untuk keperluan air minum. Parameter yang dianalisis meliputi bau, rasa, derajat keasaman $(\mathrm{pH})$, kesadahan, padatan terlarut total, kandungan nitrit, nitrat, klorida dan sulfat. Hasil kajian menunjukkan bahwa Sungai Bawah Tanah Ngancar memiliki debit $0,063 \mathrm{~m}^{3} /$ detik pada musim kemarau dan $0,077 \mathrm{~m}^{3} /$ detik pada musim penghujan, serta memiliki kualitas yang baik untuk air minum.

Kata Kunci: Potensi, Sungai Bawah Tanah, Sistem Goa Pindul, Air Minum, Kualitas Air

\section{Pendahuluan}

Kabupaten Gunungkidul sudah lama dikenal sebagai kawasan yang sering mengalami bencana kekeringan. Hal ini karena sebagian besar wilayahnya berbatuan gamping, sehingga pemenuhan kebutuhan domestik tidak dapat dilakukan dengan membuat sumur gali seperti pada wilayah lain yang memiliki material akuifer yang baik. Bentanglahan karst memiliki sistem hidrologi yang khas dan unik hasil kombinasi antara proses pelarutan (conduit) dan pergerakan air melalui rongga antar butir (diffuse) yang berkembang pada batuan yang mudah larut (Cahyadi, 2010; Cahyadi, 2014). Sedikit terdapatnya aliran sungai permukaan di wilayah karst disebabkan air hujan yang turun dan kemudian menjadi runoff masuk ke dalam system aliran sungai bawah tanah yang sangat kompleks (Cahyadi dkk, 2012). 
Sistem hidrologi yang berkembang di kawasan karst berbeda dengan kawasan non-karst, terkhususnya pada aliran airtanahnya. Aliran airtanah di kawasan non karst memiliki potensi mengalir ke semua arah sama, atau dikenal dengan istilah sistem isotropis. Sistem ini mengalirkan airtanah melewati ruang-ruang antar butir tanah/batuan. Kondisi tersebut sangat berbeda dengan sistem airtanah di kawasan karst di mana airtanahnya mengalir melewat lorong-lorong hasil proses pelarutan, atau disebut disebut anisotropis. Aliran airtanah pada sistem ini memiliki peluang air mengalir ke berbagai arah tidak sama, karena alirannya akan cenderung mengikuti retakan atau lorong hasil proses pelarutan (Cahyadi, 2014).

Perkembangan sistem hidrologi yang didominasi oleh lorong-lorong pelarutan menyebabkan bagian atas di kawasan karst memiliki kondisi yang kering, tetapi sebenarnya pada bagian bawah permukaan tersimpan sumberdaya air yang banyak (White, 1988). Meskipun potensi sumberdaya air wilayah karst yang berada di sistem bawah permukaan begitu besar, namun perlu usaha yang besar pula untuk dapat dimanfaatkan (Samodra, 2001). Cahyadi (2013) menyebutkan bahwa sumber air permukaan di wilayah karst yang dapat dimanfaatkan umumnya berupa telaga dan mataair.

Mac Donalds and Partners (1984) menyebutkan bahwa beberapa sungai bawah tanah (SBT) di Kabupaten Gunungkidul memiliki debit yang melimpah. SBT Bribin misalnya memiliki debit kurang lebih 1500 liter/detik, sedangkan SBT Seropan memiliki debit kurang lbih 400 liter/detik. Selain itu, masih terdapat beberapa SBT yang telah dimanfaatkan untuk pemenuhan kebutuhan air di Kabupaten Gunungkidul (Cahyadi dkk., 2013).

Aktivitas manusia yang berada di sekitar SBT dan mataair akan menimbulkan dampak terhadap kondisi sumberdaya airnya baik kuantitas dan kualitasnya (Cahyadi dan Hartoyo, 2011). Menurut Adji (2013), salah satu aktivitas manusia yang akan menimbulkan dampak bagi sumberdaya air di kawasan karst adalah penambangan gamping. Kegiatan ini akan akan berdampak pada perkembangan rekahan dan goa dikarenakan air yang merupakan media pealrutan batugamping juga akan terdampak (Cahyadi, 2014; Cahyadi dan Priadmodjo, 2014).

Kawasan karst memiliki tingkat kerentanan terhadap pencemaran yang lebih tinggi dibandingkan dengan bentuklahan lainnya karena adanya porositas sekunder akibat proses pelarutan. Kondisi tersebut mengakibatkan pencemar atau kontaminan airtanah pada kawasan karst tidak dapat tersaring dengan baik (Haryono dan Adji, 2004). Dikarenakan adanya proses pelarutan batuan gamping daan atau dolomit maka menurut Sudarmadji (2013) kandungan $\mathrm{CaCO}_{3}$ dan $\mathrm{MgCO}_{3}$ dalam air di kawasan 
karst lebih menonjol dibandingkan dengan tipe hidrogeokimia yang lain. Proses pelarutan erat kaitannya dengan kandungan ion dalam suatu perairan, sehingga dapat diukur dengan menggunakan nilai Daya Hantar Listrik (DHL). Semakin besar nilai DHL, maka dapat diduga bahwa kandungan ionnya juga tinggi. Nilai DHL mataair di kawasan karst berkisar antara 300 hingga $1.000 \mu \mathrm{mhos} / \mathrm{cm}$.

Air yang merupakan sumberdaya ultraessensial bagi manusia harus tersedia untuk manusia setiap saat baik secara kuantitas maupun kualitas (Cahyadi dkk., 2011). Hal ini karena hampir di setiap kegiatan manusia memerlukan air. Salah satu fungsi air yang paling mendasar bagi manusia adalah untuk air minum. Kualitas air yang digunakan untuk kebutuhan air minum memiliki standar kualitas yang paling tinggi dibandingkan dengan kebutuhan lainnya. Oleh karenanya penyediaannya seringkali memerlukan usaha yang lebih dibandingkan yang lain. Meskipun demikian, tidak berarti bahwa di alam tidak ada kuliatas air yang dapat memenuhinya.Kualitas air untuk air minum harus baik secara fisik, kimia, dan biologis agar tidak mengganggu kesehatan tubuh manusia.

Dikarenakan mataair dan SBT merupakan sumber air yang potensial untuk pemenuhan kebutuhan air minum, maka perlu dilakukan kajian terkait dengan analisis kualitas air untuk kebutuhan air minum. Penelitian ini dilakukan di SBT Ngancar di Kecamatan Karangmojo, Kabupaten Gunungkidul. Sungai Bawah Tanha Ngancar merupakan bagian dari SBT Goa Pindul (Gambar 1). Sungai Bawah Tanah Ngancar sebenarnya merupakan karst window, yakni sungai bawah tanah yang muncul sebagai mataair karena kondisi geologi, kemudian masuk kembali ke dalam sistem sungai bawah tanah. Sumberdaya air di okasi kajian perlu diuji kelayakannya agar dapat diketahui layak atau tidak untuk digunakan sebagai sumber air minum. Hal ini didasarkan pada pengamatan di lapangan bahwa SBT Ngancar telah banyak dimanfaatkan oleh masyarakat sebagai sumber air minum. 


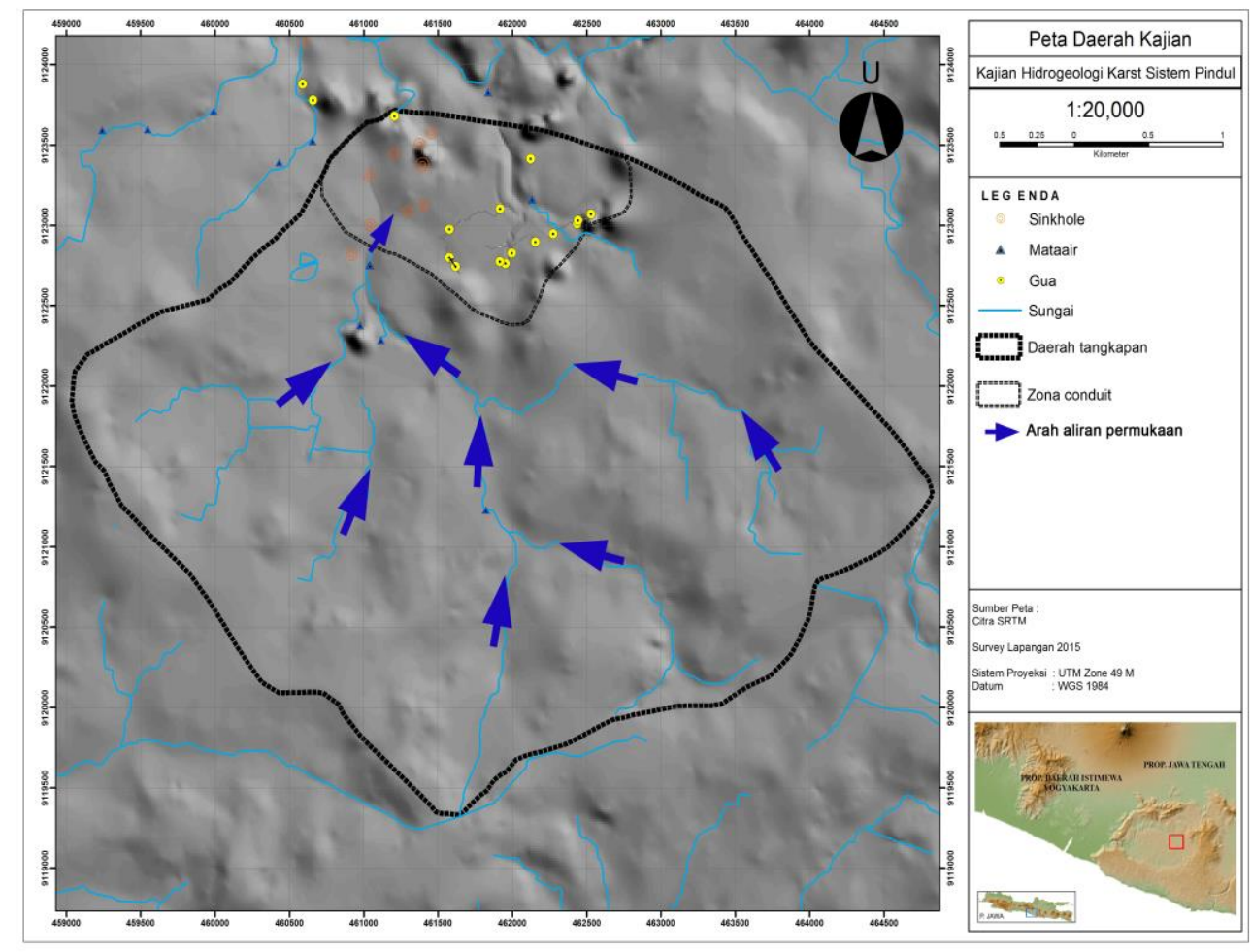

Gambar 1. Batas Daerah Tangkapan Air Sungai Bawah Tanah Goa Pindul

\section{Metode Penelitian}

\subsection{Data, Alat dan Bahan}

Data yang dibutuhkan dalam mendukung penelitian ini terdiri dari data primer dan data sekunder. Data-data tersebut ditunjukkan pada Tabel 1. Peralatan yang dibutuhkan untuk penelitian ini beserta dengan fungsinya ditunjukkan pada Tabel 2. Selanjutnya, Tabel 3 menunjukkan bahan yang dibutuhkan dalam penelitian ini.

Tabel 1. Data yang Dibutuhkan

\begin{tabular}{|l|ll|}
\hline \multicolumn{1}{|c|}{ Data Primer } & \multicolumn{1}{c|}{ Data Sekunder } \\
\hline - Data kualitas mataair & Data-data pemetaan goa-goa di \\
- Data debit sesaat & sistem Pindul \\
- Data karakteristik dan kondisi & - $\begin{array}{l}\text { Data debit mataair saat musim } \\
\text { hujan dan musim kemarau }\end{array}$ \\
\hline
\end{tabular}


Tabel 2. Alat Penelitian

\begin{tabular}{|c|c|c|}
\hline No. & Nama Alat & Fungsi \\
\hline 1. & $\begin{array}{l}\text { GPS (Global } \\
\text { Positioning } \\
\text { System) }\end{array}$ & $\begin{array}{l}\text { Mengetahui titik koordinat mataair dan lokasi } \\
\text { pengamatan }\end{array}$ \\
\hline 2. & Meteran & $\begin{array}{l}\text { Mengukur profil penampang saluran dan untuk } \\
\text { mendukung data pengukuran debit }\end{array}$ \\
\hline 3. & Pelampung & $\begin{array}{l}\text { Mengetahui kecepatan aliran dalam pengukuran } \\
\text { debit }\end{array}$ \\
\hline 4. & Ceklist Lapangan & $\begin{array}{l}\text { Mencatat hasil pengamatan dan pengukuran di } \\
\text { lapangan }\end{array}$ \\
\hline 5. & Papan Jalan & Membantu proses pencatatan di lapangan \\
\hline 6. & Kamera & $\begin{array}{l}\text { Mendokumentasikan kegiatan di lapangan dan } \\
\text { obyek penting di lapangan untuk kemudian di } \\
\text { deskripsikan dan dianlisis lebih lanjut }\end{array}$ \\
\hline 7. & $\begin{array}{l}\text { Software Google } \\
\text { Earth }\end{array}$ & Melakukan download citra satelit \\
\hline 8. & $\begin{array}{l}\text { Software } \\
\text { GlobalMapper }\end{array}$ & Mendukung pengunduhan citra satelit \\
\hline 9. & Software ArcGIS & $\begin{array}{l}\text { Melakukan pembuatan peta titik lokasi dan } \\
\text { pengolahan citra }\end{array}$ \\
\hline
\end{tabular}

Tabel 3. Bahan Penelitian yang Digunakan dalam Penelitian

\begin{tabular}{|l|l|l|}
\hline No. & Nama Bahan & Fungsi \\
\hline 1. & Citra Satelit & $\begin{array}{l}\text { Mengetahui kondisi wilayah pengamatan } \\
\text { mataair secara riil berdasarkan kondisi } \\
\text { terbarunya }\end{array}$ \\
\hline 2. & $\begin{array}{l}\text { Data peta sistem Goa } \\
\text { Pindul }\end{array}$ & $\begin{array}{l}\text { Untuk mengetahui jaringan sistem pergoaan } \\
\text { Pindul }\end{array}$ \\
\hline
\end{tabular}

\subsection{Teknik Pengumpulan Data}

Teknis pengumpulan data dalam penelitian ini dijelaskan tunjukkan pada Tabel 4. 
Tabel 4. Teknis Pengumpulan Data Penelitian

\begin{tabular}{|l|l|l|}
\hline No. & Data Penelitian & Teknis Pengumpulan Data \\
\hline 1. & Data Deskripsi Lokasi Kajian & $\begin{array}{l}\text { Melakukan pengamatan di lokasi } \\
\text { kajian terkait dengan obyek-obyek } \\
\text { yang dapat menjadi data pendukung } \\
\text { tentang karakteristik mataair }\end{array}$ \\
\hline 2. & Data Debit mataair & $\begin{array}{l}\text { Melakukan pengukuran debit sesaat di } \\
\text { lapangan dan menggunakan data } \\
\text { sekunder berupa debit pada musim } \\
\text { hujan dan musim kemarau }\end{array}$ \\
\hline 3. & Data Kualitas mataair & $\begin{array}{l}\text { Mengambil sampel air di lapangan dan } \\
\text { kemudian menguji di laboratorium } \\
\text { dengan sesuai dengan parameter- } \\
\text { parameter tertentu }\end{array}$ \\
\hline
\end{tabular}

\subsection{Teknis Analisis Data}

Teknik analisis atau metode analisis yang digunakan dalam penelitian ini adalah metode analisis deskriptif.. Metode deskriptif ini juga berlaku dalam menjelaskan kenampakan data dalam bentuk-bentuk diagram, kurva ataupun bentuk representatif data lainnya. Teknik analisis data (deskriptif) mengamati karakteristik mataair dan melakukan analisis kualitas air untuk kebutuhan air minum dan membandingkan dengan bakumutunya. Secara lebih sederhana, alur penelitian yang dilakukan dalam penelitian ini digambarkan pada Gambar 2. 


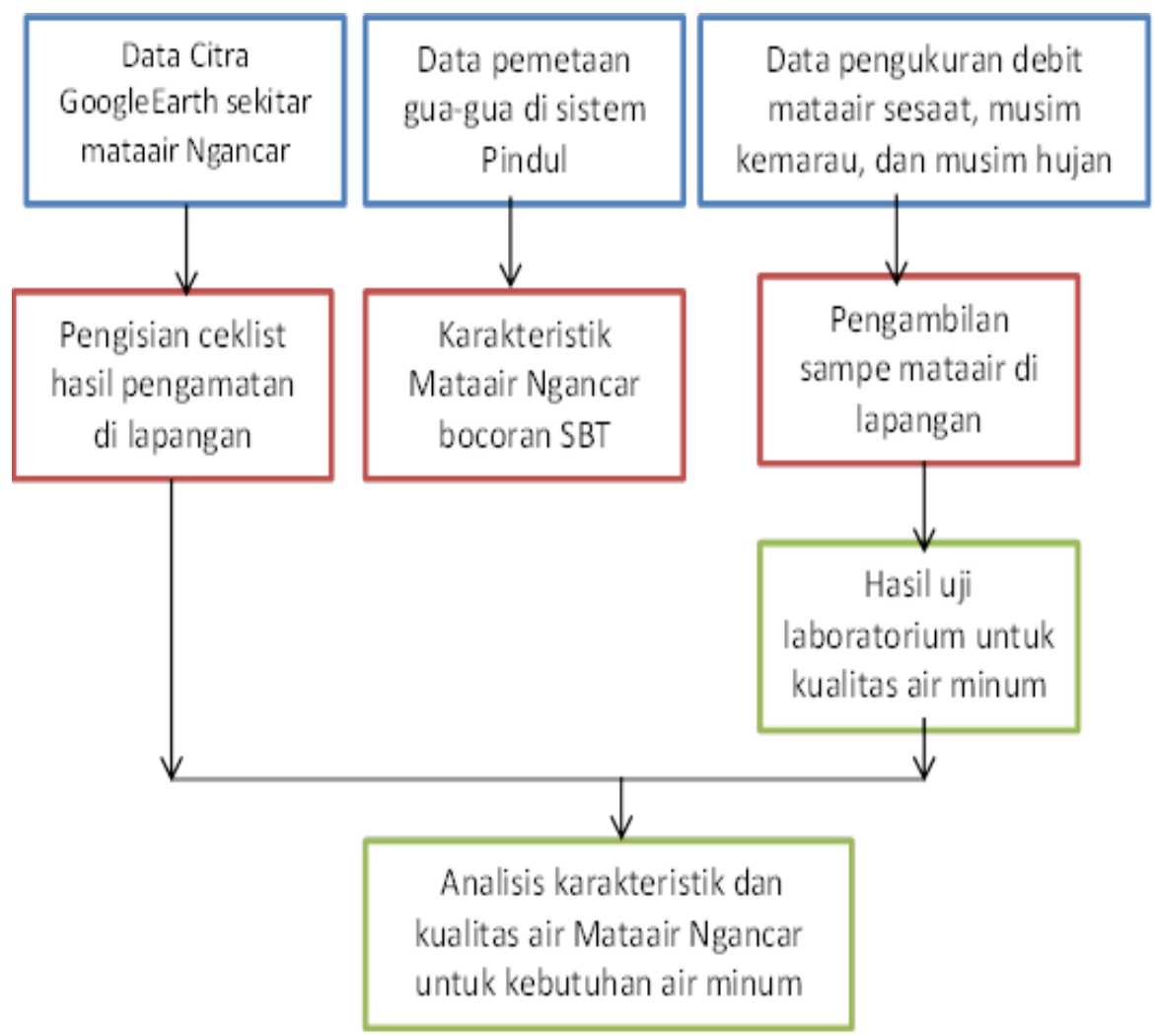

\section{Keterangan}

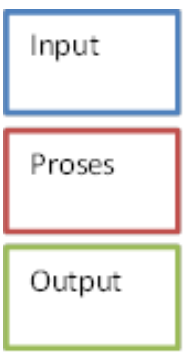

Gambar 2. Diagram Alir Penelitian

\section{Hasil dan Pembahasan}

Kondisi Sungai Bawah Tanah Ngancar cenderung alami dan belum banyak diintervensi aktivitas manusia yang merubah suatu wilayah menjadi kehilangan kesan alaminya. Penutup lahan di sekitar area SBT Ngancar berupa vegetasi rapat dan jika dilihat penggunaannya berupa kebun campuran (Gambar 3). Keberadaan permukiman pun jumlahnya masih sangat terbatas di sekitar SBT ini. Namun demikian, pada lokasi SBT ini 
terdapat sebuah bendungan kecil yang dilengkapi dengan pipa dan pompa air yang menurut hasil wawancara dengan penduduk sekitar dan petugas penjaga penampungan tersebut digunakan untuk memenuhi kebutuhan air minum penduduk di sekitarnya (Gambar 4).

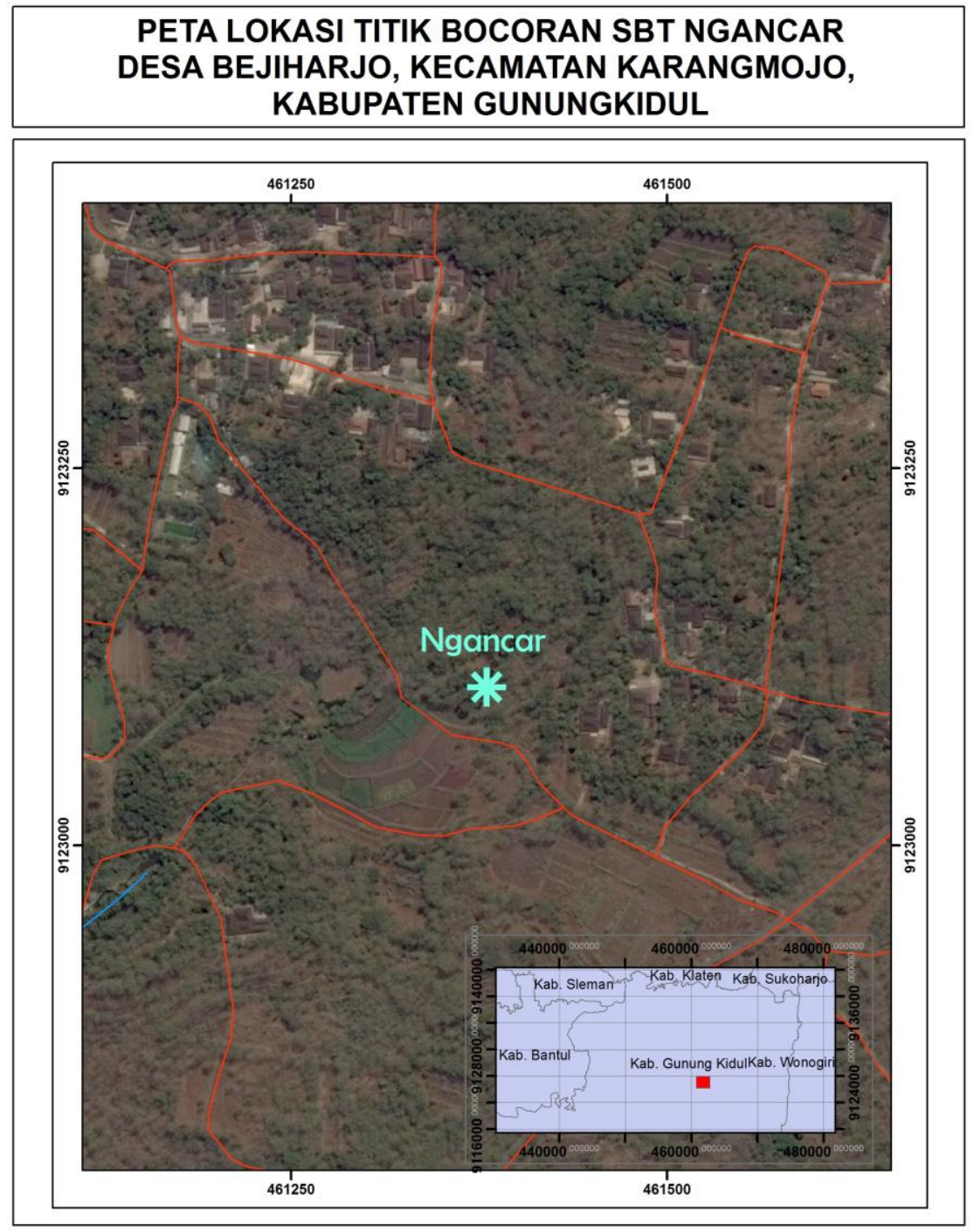

\begin{tabular}{|c|c|c|c|c|}
\hline $\begin{array}{l}\text { Legenda } \\
\text { ngancarr }\end{array}$ & & $U$ & & $\begin{array}{l}\text { Dibuat oleh: } \\
\text { Nuringtyas Yogi J }\end{array}$ \\
\hline Keterangan & & & & Sumber: Citra Google Earth 2016 \\
\hline $\begin{array}{l}\text { — Jalan } \\
\text { Sungai }\end{array}$ & 02550 & $\begin{array}{l}100 \quad 150 \\
1: 3,300\end{array}$ & 200 & $\begin{array}{l}\text { Sistem Koordinat: } \\
\text { Universal Transverse Mercator } \\
\text { Datum: WGS } 1984\end{array}$ \\
\hline
\end{tabular}

Gambar 3. Citra Lokasi SBT Ngancar dan Sekitarnya 


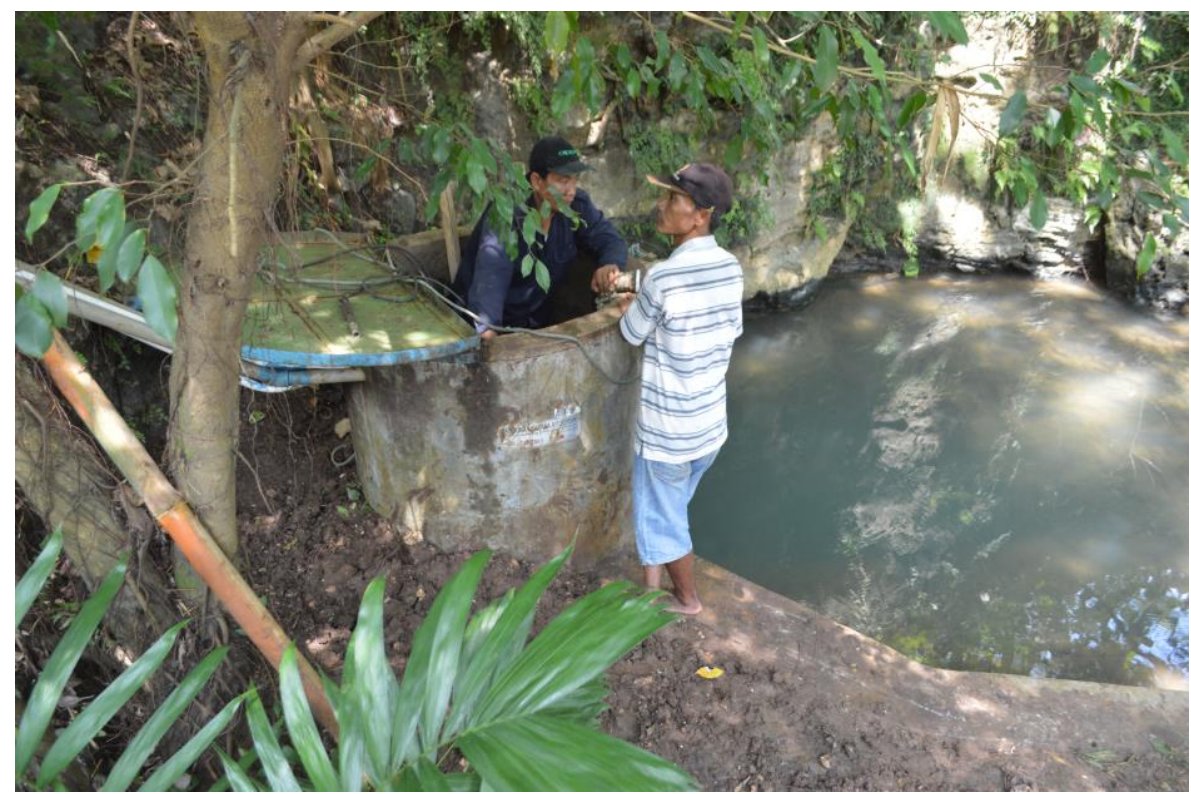

Gambar 4. Bak Penampungan Air Bersih di SBT Ngancar

Kualitas SBT Ngancar ditinjau secara terhitung baik dari hasil pengamatan baik warna, bau, rasa, suhu, dan kekeruhannya. Parameter warna, bau, rasa, dan suhu dapat diidentifikasi langsung di lapangan baik secara subyektif oleh pengamat maupun dengan alat pengukur suhu, sedangkan untuk kekeruhan yang dihitung adalah Total Dissolved Solid nya, sehingga perlu dilakukan pengukuran di lapangan. SBT Ngancar memiliki warna air yang sangat jernih hingga dasar permukaannya nampak sehingga secara baik secara estetis, airnya juga tak berasa sehingga memenuhi bakumutu air minum dan menandakan tidak banyak material atau bahan lain yang terkandung dalam air.

Sementara itu SBT Ngancar memiliki berdasarkan hasil observasi laboratorium memiliki nilai TDS $350 \mathrm{mg} / \mathrm{l}$ yang mana nilai tersebut masih berada di bawah ambang batas bakumutu untuk air minum yaitu $500 \mathrm{mg} / \mathrm{l}$. Nilai TDS memang belum dapat menggambarkan jenis mineral apa yang terkandung di dalam suatu perairan namun cukup untuk menjelaskan seberapa banyak mineral-mineral padat yang terlarut di dalam suatu perairan. Nilai TDS yang cukup tinggi dari hasil uji laboratorium di SBT Ngancar meskipun masih berada di bawah ambang batas bakumutu air minum. Dikarenakan penggunaanlahan di sekitar SBT Ngancar yang sebagian besar berupa hutan campuran dan masih sangat sedikit terpengaruh oleh aktivitas manusia maka besarnya nilai TDS tersebut 
kemungkinan disebabkan akibat terjadinya proses pelarutan karena SBT Ngancar yang terletak di kawasan Karst Gunungsewu.

Tingkat kesadahan air di SBT Ngancar terhitung cukup tinggi karena mencapai nilai 306,93 mg/l meskipun masih di bawah ambang batas bakumutu air minum yaitu $500 \mathrm{mg} / \mathrm{l}$. Kesadahan air yang terbentuk karena adanya ion kalsium dan magnesium yang berlebih mempunyai dampak positif dan negative dalam pemanfaatan airnya. Ion kalsium dan magnesium pada dasarnya dibutuhkan tubuh untuk menddukung proses perkembangan tulang sehingga apabila suatu sumberdaya air kandungan kedua ion tersebut kurang maka dapat menghambat proses perkembangan tulang. Namun apabila tingkat kesadahan air tersebut apabila suatu sumberdaya air digunakan untuk mencuci maka dapat berdampak merugikan karena suatu sumberdaya air yang memiliki tingkat kesadahan tinggi akan sulit untuk berbusa. Dikarenakan nilai kesadahan air di SBT Ngancar yang meskipun cukup tinggi namun masih berada di bawah ambang batas bakumutu airminum maka tidak akan berdampak negatif terhadap pemanfaatannya.

Tabel 5. Hasil uji sampel air dan bakumutu air minum

\begin{tabular}{|r|l|r|r|}
\hline No & \multicolumn{1}{|c|}{ Parameter } & \multicolumn{1}{|c|}{ Hasil Uji } & \multicolumn{1}{|c|}{$\begin{array}{c}\text { Baku Mutu Air } \\
\text { Minum }\end{array}$} \\
\hline 1 & Bau & Tidak Berbau & \multicolumn{1}{c|}{ Tidak Berbau } \\
\hline 2 & Rasa & Tidak Berasa & \multicolumn{1}{|c|}{ Tidak Berasa } \\
\hline 3 & $\mathrm{pH}$ & 7,30 & $6,50-8,50$ \\
\hline 4 & Kesadahan $(\mathrm{mg} / \mathrm{l})$ & 306,93 & 500,00 \\
\hline 5 & Total Disolved Solid $(\mathrm{mg} / \mathrm{l})$ & 350,00 & 500,00 \\
\hline 6 & Nitrit $(\mathrm{mg} / \mathrm{l})$ & 0,0078 & 3,00 \\
\hline 7 & Nitrat $(\mathrm{mg} / \mathrm{l})$ & 8,26 & 50,00 \\
\hline 8 & Klorida $(\mathrm{mg} / \mathrm{l})$ & 9,40 & 250,00 \\
\hline 9 & Sulfat $(\mathrm{mg} / \mathrm{l})$ & 2,00 & 250,00 \\
\hline
\end{tabular}

Sumber: Hasil analisis laboratorium

Kandungan nitrit dan nitrat di SBT Ngancar masih cukup jauh berada di bawah ambang batas bakumutu air minum nasional karena masing-masing nilainya $0,0078 \mathrm{mg} / \mathrm{l}$ untuk nitrit dengan bakumutu $3 \mathrm{mg} / \mathrm{l}$ sedangkan nitrat memiliki nilai 8,26 dengan bakumutu $50 \mathrm{mg} / \mathrm{l}$. Menurut Slamet (1996) nitrit dan nitrat berasal dari tanah, tanaman, ataupun pupuk sehingga apabila suatu lokasi memiliki kandungan nitrit dan nitrat yang tinggi maka ada kaitannya dengan keberadaan lahan pertanian di sekitarnya. 
Ditinjau dari Gambar 5., dapat dilihat bahwa meskipun sebagian besar penutup lahannya merupakan vegetasi rapat dan sebagian lainnya nampak adanya lahan pertanian namun hasil uji laboratorium menunjukkan bahwa kandungan nitrit dan nitratnya rendah. Hal tersebut dapat dipengaruhi oleh beberapa hal, yang pertama dikarenakan sistem aliran di karst yang mempunyai tipe conduit, sehingga arah alirannya sulit untuk ditebak, oleh karena itu aliran air di SBT Ngancar bisa jadi tidak berasal dari aliran air permukaan yang mengaliri lahan bervegetasi dan pertanian di sekitarnya. Yang kedua, apabila aliran berasal dari lahan pertanian disekitarnya, rendahnya kandungan nitrit dan nitrat dapat disebabkan oleh kondisi lahan pertanian yang tidak dikelola secara intensif, khususnya penggunaan pupuknya.

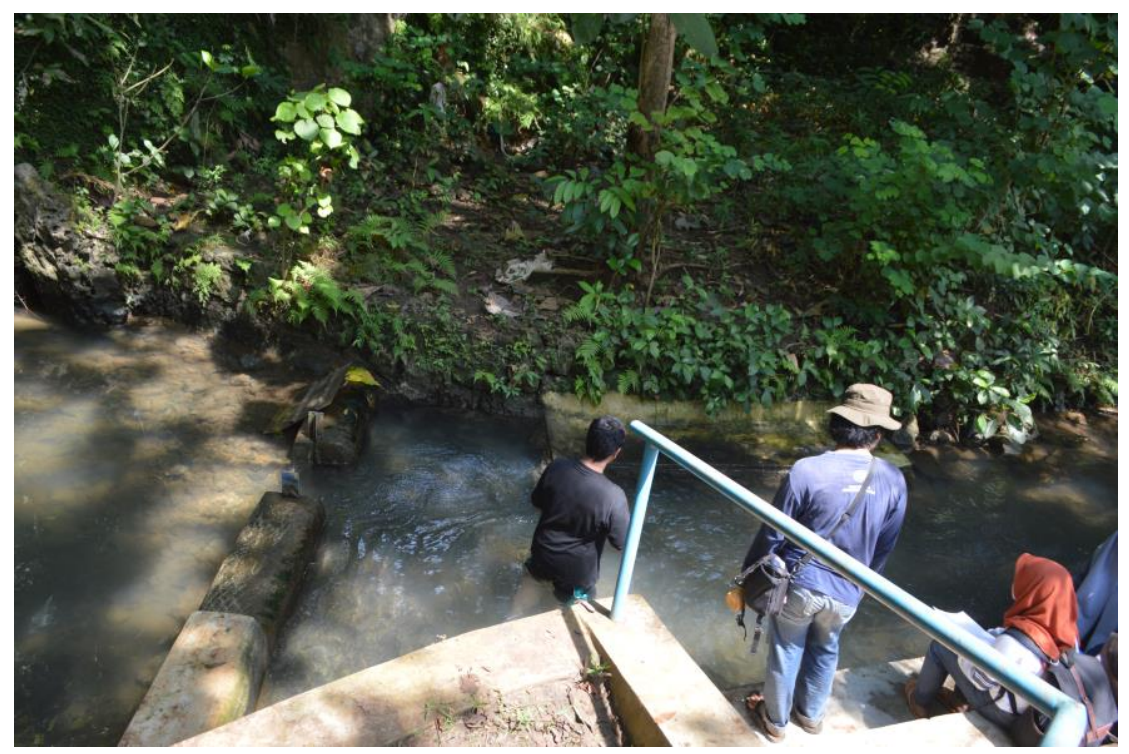

Gambar 5. Kondisi Aktual Matair Ngancar

Kandungan khlorida di SBT Ngancar memiliki nilai sebesar 9,4 mg/l yang berarti masih berada di bawah ambang batas bakumutu air minum nasional yang mencapai $250 \mathrm{mg} / \mathrm{l}$. kandungan khlorida di suatu sumberdaya air erat kaitannya dengan tingkat keasinan suatu perairan, namun dikarenakan air di SBT Ngancar tidak memiliki rasa maka kedua hal tersebut berhubungan dengan rendahnya nilai khlorida. Rendahnya kandungan khlorida juga tidak terlepas dari lokasi SBT Ngancar yang jauh dari perairan asin atau laut karena terletak di sekitar Ledok Wonosari. Selain itu rendahnya nilai khlorida juga mengindikasikan tidak ada jebakan 
perairan asin di sekitar lokasi kajian meskipun dikarenakan batuan dasar berupa batuan gamping yang mana dulunya berada di bawah permukaan air laut yang kemudian mengalami proses pengangkatan.

Hasil uji laboratorium parameter sulfat di SBT Ngancar memiliki nilai 2 $\mathrm{mg} / \mathrm{l}$ yang berarti masih memenuhi bakumutu air minum nasional karena ambang batas yang ditetapkan adalah $250 \mathrm{mg} / \mathrm{l}$. Kandungan sulfat yang melampaui ambang batas dan digunakan untuk air minum dapat mengganggu orang mengkonsumsinya karena dapat menyebabkan rasa mual dan muntah. Kandungan sulfat yang tinggi di suatu sumberdaya air sering disebabkan oleh tidak tepatnya pengelolaan limbah yang banyak mengandung bahan kimia.

Sementara itu, dilakukan pula pengukuran debit aliran SBT Ngancar secara incidental dalam dua kali waktu, yaitu pada musim penghujan dan musim kemarau. Pada musim kemarau debit alirannya yaitu $0,063 \mathrm{~m}^{3} /$ detik atau mencapai $5443,2 \mathrm{~m}^{3}$ setiap harinya. Sedangkan pada musim penghujan debit alirannya $0,077 \mathrm{~m} 3 /$ detik atau $6652 \mathrm{~m}^{3} /$ hari. Jika diasumsikan kebutuhan air penduduk adalah 70 liter/hari maka lokasi kajian dapat memenuhi paling tidak dapat memenuhi kebutuhan penduduk sebanyak 50.000 orang atau setara dengan jumlah penduduk Kecamatan Karangmojo pda tahun 2014.

\section{Kesimpulan}

Berdasarkan hasil kajian yang telah dilakukan, maka dapat disimpulkan beberapa hal berikut:

1. Sungai Bawah Tanah Ngancar memiliki debit $0,063 \mathrm{~m}^{3} /$ detik pada musim kemarau dan $0,077 \mathrm{~m}^{3} /$ detik pada musim penghujan; dan

2. Berdasarkan hasil parameter baik yang diukur di lapangan maupun yang diuji di laboratorium Bocoran SBT Ngancar layak untuk digunakan sebagai sumber air minum.

\section{Pengakuan}

Penelitian ini merupakan bagian dari hibah Penelitian Unggulan Perguruan Tinggi (PUPT) Kementerian Riset, Teknologi dan Pendidikan Tinggi (Kemenristekdikti) tahun 2016 yang berjudul "Karakterisasi Hidrologi dan Banjir di Sungai Bawah Tanah Goa Pindul untuk Pengelolaan Pariwisata Berkelanjutan Berbasis Manajemen Kebencanaan" dengan nomor kontrak 679/UN1-P.III/LT/DIT-LIT/2016. 


\section{Daftar Pustaka}

Adji, T.N. 2013. Kondisi Daerah Tangkapan Sungai Bawah Tanah Karst Gunungsewu dan Kemungkinan Dampak Lingkungannya Terhadap Sumberdaya Air (Hidrologis) karena Aktivitas Manusia. dalam Sudarmadji; E. Haryono; Adji, T.N.; Widyastuti, M.; Harini, R.; Nurjani, E.; Cahyadi, A. dan Nugraha, H. (editor). Ekologi Lingkungan Kawasan Karst Indonesia: Menjaga Asa Kelestarian Kawasan Karst Indonesia. Yogyakarta: Deepublish.

Agniy, R.F dan Haryono, E. 2016. Kajian Hidrogeologi Karst Sistem Goa Pindul, Kecamatan Karangmojo, Kabupaten Gunungkidul. Skripsi. Yogyakarta: Fakultas Geografi Universitas Gadjah Mada.

Cahyadi, A. 2010. Pengelolaan Kawasan Karst dan Peranannya dalam Siklus Karbon di Indonesia. Prosiding Seminar Nasional Perubahan Iklim. Yogyakarta: Sekolah Pascasarjana Universitas Gadjah Mada.

Cahyadi, A. Priadmodjo, A. and Yananto, A. 2011. Criticizing The Conventional Paradigm of Urban Drainage. Proceeding The 3rd International Graduated Student Conference on Indonesia. Yogyakarta: Graduate School, Universitas Gadjah Mada.

Cahyadi, A. 2013. Tingkat Pengetahuan Masyarakat Terhadap Keberadaan dan Penyebab Kerusakansumberdaya Air Sungai Bawah Tanah di Kawasan Karst Gunungsewu. Geomedia, 11(2): 253 - 260.

Cahyadi, A.; Ayuningtyas, E.A. dan Prabawa, B.A. 2013. Urgensi Pengelolaan Sanitasi dalam Upaya Konservasi Sumberdaya Air di Kawasan Karst Gunungsewu Kabupaten Gunungkidul. Indonesian Journal of Conservation, 2(1): 23-32.

Cahyadi, A. 2014. Keunikan Hidrologi Kawasan Karst: Suatu Tinjauan. dalam Cahyadi, A.; Prabawa, B.A.; Tivianton, T.A. dan Nugraha, H. 2014. Ekologi Lingkungan Kawasan Karst Indonesia: Mejaga Asa Kelestarian Kawasan Karst Indonesia, Edisi 2. Yogyakarta: Deepublish. Hal: $1-13$.

Cahyadi, A. dan Priadmodjo, A. 2014. Pengaruh Penambangan Gamping Terhadap Fungsi Penyerapan Karbondioksida $\left(\mathrm{CO}_{2}\right)$ Atmosfer di Kawasan Karst Kecamatan Ponjong, Kabupaten Gunungkidul. Prosiding Seminar Nasional Geospatial Day. Surakarta: Prodi Pendidikan Geografi, Universitas Sebelas Maret.

Haryono, E. dan Adji, T.N. 2014. Geomorfologi dan Hidrologi Karst. Yogyakarta: Kelompok Studi Karst Fakultas Geografi UGM.

Mac Donalds and Partners. 1984. Greater Yogyakarta - Groundwater Resources Study. Vol 3C: Cave Survey. Yogyakarta: Direktorat Jenderal Pengembangan Sumberdaya Air 
Rosaji, F.S.C. dan Cahyadi, A. 2012. Deteksi Telaga Potensial untuk

Pemenuhan Kebutuhan Air Musim Kemarau di Kawasan Karst Menggunakan Data Penginderaan Jauh Multitemporal. Prosiding Simposium Nasional Sains Informasi Geografis. Yogyakarta: Fakultas Geografi UGM.

Samodra, H. 2001. Nilai Strategis Kawasan Karst. Jakarta: Departemen Energi dan Sumbedaya Mineral

Slamet, J.S. 1996. Kesehatan Lingkungan. Yogyakarta: Gadjah Mada University Press

Sudarmadji. 2013. Mata Air: Perspektif Hidrologis dan Lingkungan. Yogyakarta: Sekolah Pascasarjana Univeristas Gadjah Mada.

White, W.B., 1988. Geomorphology and Hydrology of Karst Terrain. New York: Oxford University Press.

Makalah ini merupakan bagian dari Buku Seri Bunga Rampai dengan Judul "Hidrologi dan Kepariwisataan Kawasan karst Goa Pindul Kabupaten Gunungkidul" dengan Editor Slamet Suprayogi, Setyawan Purnama, Ahmad Cahyadi, Hendy Fatchurohman. Buku ini diterbitkan oleh Badan Penerbit Fakultas Geografi (BPFG) Universitas Gadjah Mada di Yogyakarta Tahun 2016. Makalah ini termuat dalam Halaman 18-32. 